Indonesian Journal of Medicine (2019), 4(2): 82-87

https://doi.org/10.26911/theijmed.2019.04.02.01

\title{
Cardiopulmonary Resuscitation Guideline Update: A Systematic Review
}

\author{
Joko Tri Atmojo, Aris Widiyanto, Rina Tri Handayani
}

School of Health Sciences Mamba'ul 'Ulum, Surakarta

\begin{abstract}
Background: Every five years, the American Heart Association (AHA) releases new guidelines on CPR. Previous guidelines have focused on Airway-Breathing-Circulation (ABC) advocacy. However, in 2010 guidelines for CPR recommended changes in the sequence of BLS steps to $\mathrm{CAB}$ (chest compression, airway, and breathing) for adults, children and infants (excluding newborns). The purpose of this review is to explain the reasons and provide scientific evidence about the results of $\mathrm{CAB}$ actions compared to $\mathrm{ABC}$.

Subjects and Method: Systematic reviews were done by searching the database through PubMed, Google Scholar, and Science Direct. Key words for this review include: AHA Guideline AND CPR 2010, CAB in CPR, CAB, and RCT (Randomized Controlled Trial) guidelines and why does $\mathrm{ABC}$ turn into $\mathrm{CAB}$ ? The inclusion criteria are systematic reviews, clinical reviews and guidelines.

Results: The results are in the form of 3 review articles and 1 RCT study. The basic reasons for changing $\mathrm{ABC}$ to $\mathrm{CAB}$ are (1) The most common case of cardiac arrest in adults, and the initial element of critical BLS (basic life support) is chest compression and early defibrillation by changing sequentially to $\mathrm{CAB}$, chest compression will start faster; (2) Most victims of cardiac arrest outside the hospital do not get CPR observers, this is an obstacle to opening the airway and exhaling; and (3) Chest compression provides vital blood flow to the heart and brain. One RCT study showed that the time to do the first resuscitation with the CAB technique (mean = 25; $\mathrm{SD}=10$ ) was faster than the $\mathrm{ABC}$ technique (mean $=32 ; \mathrm{SD}=12$ ) and statistically significant ( $=0.002$ ).
\end{abstract}

Conclusions: Chest compression is the most important aspect of heart attack management because airway maneuver takes a long time. The time to complete the first resuscitation cycle on $\mathrm{CAB}$ action is shorter than using $\mathrm{ABC}$ actions.

Keywords: ABC, CAB, CPR guidelines, systematic review

\section{Correspondence:}

Joko Tri Atmojo. School of Health Sciences Mamba'ul 'Ulum, Surakarta, Jl. Ring Road Utara, Tawangsari, Mojosongo, Jebres, Surakarta, Central Java. Email: jokotriatmojo1@gmail.com. Mobile: +6281393319000

\begin{tabular}{l}
\hline BACKGROUND \\
\hline Cardiovascular disease remains the \\
leading cause of death worldwide, with \\
half the incidence being sudden heart \\
attacks (Khalid et al., 2010). In the United \\
States, every year 330,000 people die of \\
coronary heart disease and of that \\
number, 150,ooo cases are sudden heart \\
attacks that occur outside the hospital \\
(Thom et al., 2006). \\
Basic life support (BLS) is the basis \\
for saving lives after cardiac arrest. Fun-
\end{tabular}

damental aspects of BLS include the introduction of sudden cardiac arrest (SCA) and activation of an emergency response system that is very important cardiac resuscitation (CPR) or cardiopulmonary resuscitation (CPR) controlled by all health personnel because CPR delay and defibrillation can decrease opportunities to survive $7 \%$ to $10 \%$ every minute. (Goddard et al., 2010). Unfortunately, only $15-30 \%$ of effective CPR is done to victims (Abella et al., 2008). 
The American Health Association (AHA) guidelines recommend changes in the BLS step sequences from ABC (Airway, Breathing, Chest compressions) to $\mathrm{CAB}$ (Chest compressions, Airway, and Breathing) for adults, children, and baby (not including new baby). This fundamental change in the CPR sequence makes all people who have studied CPR have to do education and retraining (Affecting et al., 2010).

However, whether the fundamental reasons for this change and whether there empirical evidence that makes consensus from the experts involved in making the 2010 AHA Guidelines believe this change will bring success in the effort to save the occurrence of impromptu heart attacks. In this review the researchers explain the reasons and scientific evidence about the effects of $\mathrm{CAB}$ compared to $\mathrm{ABC}$.

\section{SUBJECTS AND METHOD}

This systematic review was carried out in accordance with the Selected Reporting Items for the Systematic Review of the Preferred Reporting Items for Systematic Reviews and Meta-Analyzes (PRISMA) (Liberati et al., 2009).

Systematic database searches were conducted from March 20 to December 10 2018. Databases include PubMed, google scholar and Science Direct. Key words for this review included: AHA Guideline AND CPR 2010, $\mathrm{CAB}$ in $\mathrm{CPR}, \mathrm{CAB}$ and $\mathrm{RCT}$ guidelines, and why does $\mathrm{ABC}$ turn into $\mathrm{CAB}$ ? The inclusion criteria include: articles with a type of systematic review, clinical review (especially RCT), and technical implementation guidelines (guidelines).

\section{RESULTS}

Based on the Preferred Reporting Items for Systematic Reviews and Meta-Analyzes (PRISMA), a total of 558 articles were identified during the initial search of the entire database. After eliminating duplicates and applying exclusion criteria, 55 articles were analyzed further. After carefully examining the full text article, finally 4 articles were included for further discussion involving 1 clinical trial article with RCT design, a search summary can be seen in (Figure 1).

\section{Reasons for the change in $\mathrm{ABC}$ to be CAB}

High-quality CPR can effectively improve the outcome and survival of heart failure patients because of its contribution to improving blood flow, oxygen and energy delivery, successful defibrillation and return of spontaneous circulation (Liu et al., 2018). Therefore, for the reasons the AHA continues to improve CPR measures according to (Affecting et al., 2010), including:

a. Chest compression provides vital blood flow to the heart and brain.

b. Most victims of cardiac arrest outside the hospital do not get CPR observers, this is an obstacle to opening the airway and exhaling

c. Studies of adult cardiac arrest patients outside the hospital show that survival rates are higher when chest compressions are performed.

d. Chest compression can be started immediately, while positioning the head and carrying out mouth-to-mouth breathing or breathing bag-mask breathing takes time.

e. The most common cases of cardiac arrest in adults, and the initial element of critical BLS (basic life support) is chest compression and early defibrillation by changing sequentially to $\mathrm{CAB}$, chest compression will start faster

Most victims of cardiac arrest outside the hospital do not get CPR observers, this is an obstacle to opening the airway and exhaling. 


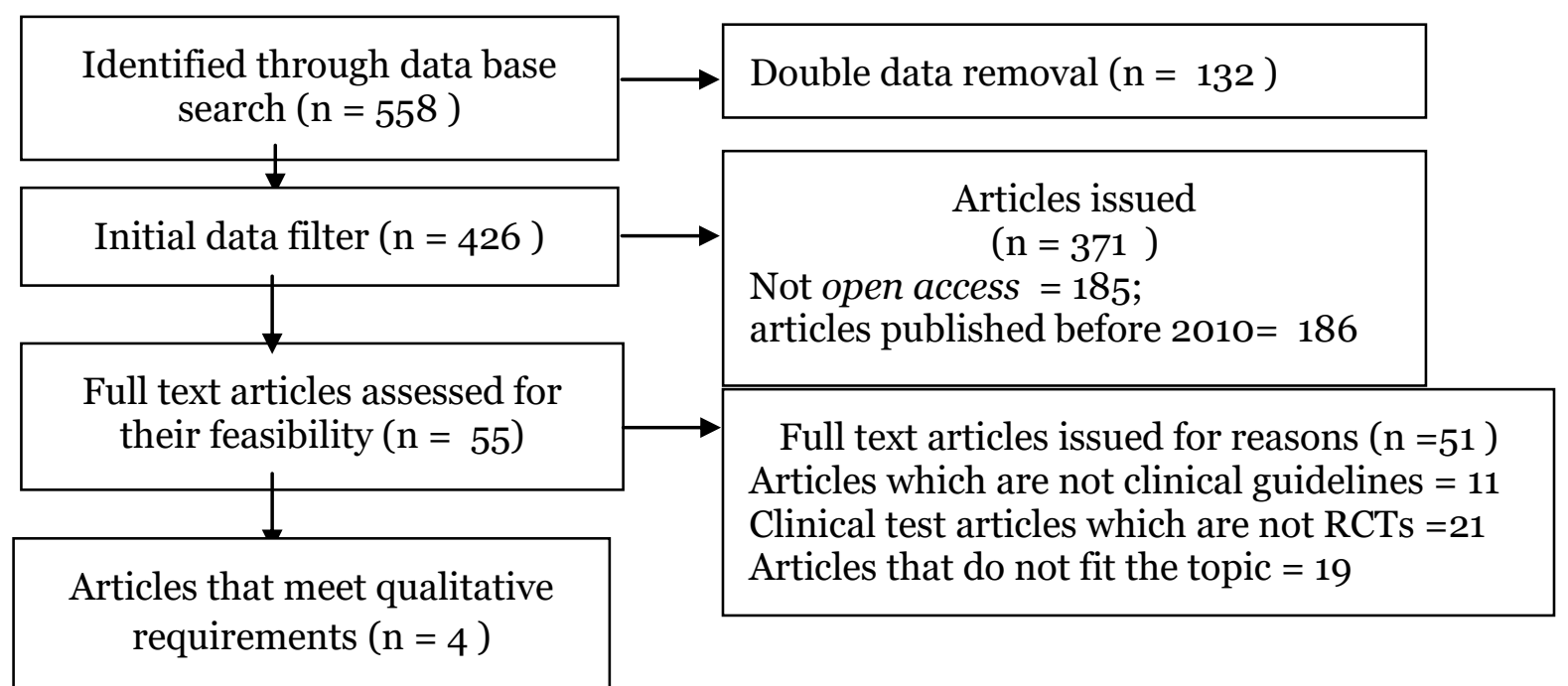

\section{Figure 1. Literature Review Procedure}

\section{Changes to the CPR guidelines}

On November 2, 2010, there has been a paradigm shift towards making the first compression. This Recommendation has been consulted by at least 356 resuscitation experts from 29 countries who reviewed and analyzed the data for 36 months (Field et al., 2010). Other changes in the 2010 to 2015 implementation guidelines are as follows:

a. 'Look, Listen and Feel' has been removed from the basic life support (BLS) algorithm as it was found to be inconsistent and a waste of time (Khalid, Abdul and Juma, 2010; Berg et al, 2010).

b. The recommended sequence for the only confirmed helper is starting with chest compression before giving artificial respiration (C-A-B instead of A-BC). The CPR action begins with 30 chest compressions followed by 2 artificial breaths (Pedoman and Heart, 2015; Hauk, 2016).

c. The depth of compression for adults has increased to at least 2 inches $(5 \mathrm{~cm})$ but not deeper than 2.4 inches $(6 \mathrm{~cm})$ and for children at least 1.5 inches (Khalid, Abdul, and Juma, 2010; Hauk, 2016). d. More emphasis on teamwork and training (Khalid, Abdul, and Juma, 2010).

e. The recommended chest compression speed is $100 / \mathrm{min}$ to $120 / \mathrm{min}$.

f. For adults who have a heart attack and receive CPR without advanced airways, it may be necessary to do CPR targeting the highest possible chest compression fraction, a minimum of $60 \%$.

g. The combination of vasopressin and epinephrine does not provide any benefit in the use of standard-dose apinephrine, so vasopressin administration has been removed in the adult RJP algorithm.

h. Low end-tidal carbon dioxide (ETCO2) can be considered after 20 minutes of CPR action.

i. Steroids can provide several benefits when combined with vasopressin and epinephrine in patients of Hospital cardiac arrest (HCA).

\section{Clinical trials of CAB superiority compared to $\mathrm{ABC}$}

In determining a guideline, a clinical trial with a randomized controlled trial (RCT) was needed before and after a guideline was applied.

CPR was a cheap action that can save someone's life, so recommendations 
for change must be supported by strong evidence. The highest level of proof quality (A) and level B required at least 1 clinical trial with an RCT design.

The author investigated the RCT clinical trial before the 2015 AHA guidelines were launched to strengthen the changes made in the previous 2010 guidelines. The RCT test conducted (Marsch et al., 2013) involved 108 teams, each consisting of two doctors, who were randomized to receive a graphical display of the $\mathrm{ABC}$ algorithm or the $\mathrm{CAB}$ algorithm.
Furthermore, the team had to implement CPR in cases of simulated cardiac arrest.

This study was conducted from 2007-2010. After the publication of the 2010 guidelines advocate the $\mathrm{CAB}$ approach. Teams were allocated randomly with closed envelopes to receive one of the two graphic instruction versions of the resuscitation algorithm, namely: $\mathrm{ABC}$ or CAB. Participants receive 15 minutes of standard instruction from the patient simulator.

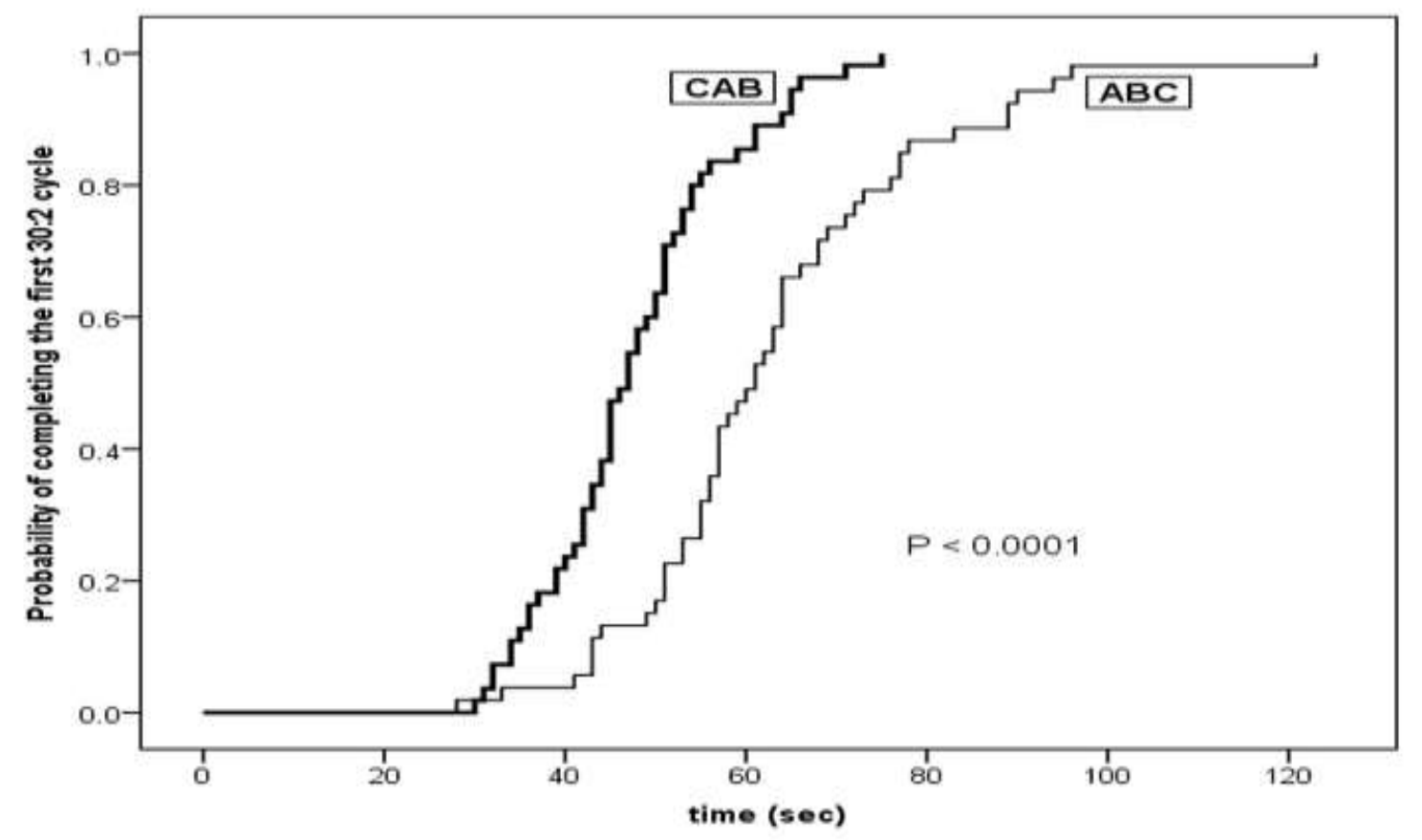

Figure 2. Probability to complete the first resuscitation cycle Source: Marsch et al. (2013)

After the simulation, participants were given a questionnaire and asked to rate the algorithms previously received on a 10-point Likert scale with respect to: (1) perceived benefits of the algorithm in dealing with experienced scenarios (o = totally useless, 10 = very useful); and (2) perceived easiness by the algorithm in the scenario experienced ( 0 = very easy, $10=$ very difficult).

Data analysis was performed by using video recordings for the first 30 compression resuscitation cycles and two vents which were obtained during the simulation by two independent observers (one nurse and one doctor, both intensive nurses with regular exposures to CPR in real cases). The difference between observers in the event time $\leq 5$ seconds was considered an agreement. The difference between observers in the event time $>5$ seconds was completed by jointly reviewing the video footage. The first touch of the patient by one participant was defined 
as the starting point for determining the time of all incidents.

The results showed that the timing of the first resuscitation measurement was $32 \pm 12$ seconds on the $\mathrm{ABC}$ team and 25 \pm 10 seconds in the CAB team $(\mathrm{p}=0.002)$. $18 / 53 \mathrm{ABC}$ Team (34\%) and none of the $55 \mathrm{CAB}$ teams $(\mathrm{p}=0.006)$ applied more than two recommended initial rescue breaths which led to a longer duration of the first cycle of 30 compression and two ventilation in the $\mathrm{ABC}$ team ( $31 \pm 13$ vs. 23 \pm 6 seconds $)(p=0.001)$. Overall, the time to complete the first resuscitation cycle was longer in the $\mathrm{ABC}$ team $(63 \pm 17 \mathrm{vs} 48$ \pm 10 seconds $(\mathrm{p}<0.001)$.

Therefore, based on the results of this RCT test, $\mathrm{CAB}$ was superior to $\mathrm{ABC}$ because $\mathrm{CAB}$ gave earlier $\mathrm{CPR}$ results and a shorter time to complete the first resuscitation cycle 30: 2 (Figure 2).

\section{DISCUSSION}

Revisions to current CPR guidelines were not without consideration. Because the majority of CPR success occurred in adults and an important element for survival in it was chest compression (Rea et al., 2010).

In the A-B-C sequence, chest compression was often delayed because of the complexity of the airway examination. By changing the order to C-A-B, chest compression would start faster, this would increase the success rate of $\mathrm{CPR}$ and survival for a heart attack.

Although the number and quality of supporting data wa still limited, especially in children, infants and pregnant women. But maintaining the $\mathrm{CAB}$ technique still needed to be done. Maintaining the same sequence in providing CPR care to adult and child patients would create consistency in teaching (Pedoman and Heart, 2015).
Provision of epinephrine and vasopressin has indeed been shown to increase return of spontaneous circulation (ROSC), but the examination has proven that the efficacy of these two drugs was the same and there was no significant additional benefit from the administration of both (Guidelines and Heart, 2015), so as to provide convenience, vasopressin has been removed from the algorithm of heart attack in adult patients.

In predicting CPR failure that has been done for 20 minutes, it can still be seen from the failure of ETCO2 achievement of $10 \mathrm{mmHg}$ by capnography, however, study was still limited to various confounding potentials and relatively small number of research subjects (Guidelines and Hearts, 2015), so it was advisable to not only rely on achieving ETCO2.

However, until now Chest Compression was the most important aspect of heart attack management because airway maneuver took a long time. In addition, a randomized controlled trial found that $\mathrm{CAB}$ was superior to $\mathrm{ABC}$ with a shorter time to complete the first resuscitation cycle.

Various advantages and limitations in clinical trials made the researchers still have the opportunity to develop and replicate existing research and clinical trials in order to achieve maximum success from efforts to save heart failure patients through CPR. Randomized clinical trials (RCTs) in children, infants and pregnant women were still very much needed in improving guidelines and strengthening scientific evidence.

\section{REFERENCE}

Abella BS, Aufderheide TP, Eigel B, Hickey RW, Longstreth jr, Nadkarni V. et al. (2008). Reducing barriers for implementation of bystander-initiated cardiopulmonary resuscitation 
a scientific statement from the american heart association for healthcare providers, policymakers, and community leaders regarding the effectiveness of cardiopulmona. Circulation, 117(5): 704-709.

Affecting MI, Sayre MR, Berg MD, Berg RA, Bhanji F, Billi JE, et al. (2010). Highlights of the 2010 American Heart Association Guidelines for CPR and ECC. American Heart Association. http://www.heart.org/idc/groups/heart-public/@wcm/@ecc/documents/downloadable/ucm 317350 .pdf.

Berg RA, Hemphill R, Abella BS, Cave DM, Hazinki MF, Lemer B. et al. (2010). American Heart Association Guidelines for Cardiopulmonary Resuscitation and Emergency Cardiovascular Care. American Health Association. s685-s702.

Field JM, Hazinski MF, Sayre MR, Chameides L, Schexnayder SM, Hemphill R, Samson RA, Kattwinkel J, et al. (2010). Part 1: Executive summary: 2010 American Heart Association Guidelines for Cardiopulmonary Resuscitation and Emergency Cardiovascular Care. Circulation. 122(18): S640-56. doi: 10.1161/CIRCULATIONAHA.110.970889.

Goddard KB, Eppert HD, Underwood EL, Maxwell K, Finks SW, Rogers KC (2010). Basic life support and cardiopulmonary resuscitation training for pharmacy students and the community by a pharmacy student committee. American Journal of Pharmaceutical Education, 74(6): 1-4.

Hauk L (2016). AHA updates guidelines for CPR and emergency cardiovascular care. American Family Physician, 93(9): 796-797.
Khalid U, Abdul A, Juma M (2010). Paradigm shift: "ABC" to "CAB" for cardiac arrests. Scandinavian Journal of Trauma, Resuscitation and Emergency Medicine, 18(1): 59.

Liberati A, et al. (2009). The PRISMA statement for reporting systematic reviews and meta-analyses of studies that evaluate healthcare interventions: explanation and elaboration. Bmj, 339(1): b270o-b270o.

Liu Y, Huang Z, Li H, Zheng G, Ling Q, Tang W, et al. (2018). CPR feedback/prompt device improves the quality of hands-only CPR performed in manikin by laypersons following the 2015 AHA guidelines. 1-24. Elsevier Inc.

Marsch S, Tschan F, Semmer NK, Zobrist R, Hunzicker P, Hunzicker S (2013). $A B C$ versus $C A B$ for cardiopulmonary resuscitation: A prospective, randomized simulator-based trial. Swiss Medical Weekly.

Pedoman P, Heart A (2015). Fokus utama pembaruan pedoman American Heart Association 2015 untuk CPR dan ECC. American heart Association.

Rea TD, et al. (2010). Predicting survival after out-of-hospital cardiac arrest: Role of the Utstein Data Elements. Annals of Emergency Medicine. 55(3): 249-257. Doi: https://doi.org/10.1016/j.annemergmed.2009.09.018

Thom T, Haase N, Rosamond W, Howard VJ, Rumsfeld J, MManolio T, et al. (2006). Heart Disease and Stroke Statistics-2006 Update, Circulation. American Heart Association. 113(6): e85-151. Doi: https://doi.org/10.1161/CIRCULATIONAHA.105.171600. 